Article

\title{
Influence of Membrane Equivalent Weight and Reinforcement on Ionic Species Crossover in All-Vanadium Redox Flow Batteries
}

\author{
Yasser Ashraf Gandomi ${ }^{1}$, Doug S. Aaron ${ }^{1}$ and Matthew M. Mench ${ }^{1,2, *}$ \\ 1 Electrochemical Energy Storage and Conversion Laboratory, Department of Mechanical, Aerospace and \\ Biomedical Engineering, University of Tennessee, Knoxville, TN 37996, USA; yashrafg@utk.edu (Y.A.G.); \\ daaron@utk.edu (D.S.A.) \\ 2 Energy and Transportation Science Division, Oak Ridge National Laboratory, Oak Ridge, TN 37831, USA \\ * Correspondence: mmench@utk.edu; Tel.: +1-865-974-5115
}

Academic Editor: Jerry Meldon

Received: 3 May 2017; Accepted: 2 June 2017; Published: 6 June 2017

\begin{abstract}
One of the major sources of lost capacity in all-vanadium redox flow batteries (VRFBs) is the undesired transport (usually called crossover) of water and vanadium ions through the ion-exchange membrane. In this work, an experimental assessment of the impact of ion-exchange membrane properties on vanadium ion crossover and capacity decay of VRFBs has been performed. Two types of cationic membranes (non-reinforced and reinforced) with three equivalent weights of 800, 950 and $1100 \mathrm{~g} \cdot \mathrm{mol}^{-1}$ were investigated via a series of in situ performance and capacity decay tests along with ex situ vanadium crossover measurement and membrane characterization. For non-reinforced membranes, increasing the equivalent weight (EW) from 950 to $1100 \mathrm{~g} \cdot \mathrm{mol}^{-1}$ decreases the V(IV) permeability by $\sim 30 \%$, but increases the area-specific resistance (ASR) by $\sim 16 \%$. This increase in ASR and decrease in V(IV) permeability was accompanied by increased through-plane membrane swelling. Comparing the non-reinforced with reinforced membranes, membrane reinforcement increases ASR, but V(IV) permeability decreases. It was also shown that there exists a monotonic correlation between the discharge capacity decay over long-term cycling and V(IV) permeability values. Thus, $\mathrm{V}(\mathrm{IV})$ permeability is considered a representative diagnostic for assessing the overall performance of a particular ion-exchange membrane with respect to capacity fade in a VRFB.
\end{abstract}

Keywords: vanadium redox flow battery; crossover; equivalent weight; reinforcement; swelling; conductivity; UV-Vis spectroscopy

\section{Introduction}

Incorporating non-hydroelectric renewable energy sources (e.g., solar and wind power) into the electric grid requires robust and large-scale energy storage systems. Redox flow batteries (RFBs) are promising candidates for efficient, large-scale energy storage. Among many chemistries developed for RFBs, all-vanadium redox flow batteries (VRFBs) are the focus of this study. VRFBs are unique among all major chemistries developed for RFBs since they utilize the same ion (vanadium) in multiple oxidation states for negative and positive electrolytes; as a result, they do not suffer from irreversible capacity decay due to vanadium ion transport through the ion-exchange membrane [1]. VRFB systems were initially proposed by Skyllas-Kazacos and co-workers, and significant improvements have been made in increasing the power density and the performance via different research groups [2-6]. Typical VRFB systems have an energy density of $25-30 \mathrm{Wh} \cdot \mathrm{kg}^{-1}$ and a round-trip efficiency of $70 \%-80 \%$, depending on operating current. Recently, a high performance VRFB cell with up to $88 \%$ energy efficiency at a current density of $400 \mathrm{~mA} \cdot \mathrm{cm}^{-2}$ has been demonstrated successfully [2,7-10]. 
Although significant progress has been made in improving the performance of VRFBs, there are many issues yet to be addressed. One of the major remaining issues is the relatively rapid capacity decay during cycling compared to expected component lifetime. The primary contributions to capacity loss are undesired vanadium and water transport through the ion-exchange membrane, degradation of cell components (predominantly electrodes and membrane) and gas-generating side reactions [11-13]. Appropriate material selection, pretreatment protocol, and operating voltage range can largely avoid material degradation and side reactions. However, capacity decay due to vanadium and water transport across the membrane is inevitable. For VRFB systems, the following reactions are reported to occur when vanadium ions cross through the membrane [14].

$$
\begin{aligned}
\mathrm{V}^{2+}+2 \mathrm{VO}_{2}^{+}+2 \mathrm{H}^{+} & \rightarrow 3 \mathrm{VO}^{2+}+\mathrm{H}_{2} \mathrm{O} \\
\mathrm{V}^{2+}+\mathrm{VO}^{2+}+2 \mathrm{H}^{+} & \rightarrow 2 \mathrm{~V}^{3+}+\mathrm{H}_{2} \mathrm{O} \\
\mathrm{VO}_{2}^{+}+\mathrm{V}^{3+} & \rightarrow 2 \mathrm{VO}^{2+} \\
\mathrm{VO}_{2}^{+}+2 \mathrm{~V}^{2+}+4 \mathrm{H}^{+} & \rightarrow 3 \mathrm{~V}^{3+}+2 \mathrm{H}_{2} \mathrm{O}
\end{aligned}
$$

Reactions (1) and (2) correspond to the case where vanadium ions of the positive electrolyte $(\mathrm{V}(\mathrm{IV})$ and $\mathrm{V}(\mathrm{V}))$ cross through the ion-exchange membrane and react with $\mathrm{V}(\mathrm{II})$ in the negative electrolyte. A similar case occurs when the vanadium ions of the negative electrolyte (V(II) and V(III)) travel through the membrane and react with $\mathrm{V}(\mathrm{V})$ in the positive electrolyte according to Reactions (3) and (4).

Several parameters contribute to capacity decay due to solute (vanadium ion) and solvent (water) transport through the membrane. The properties of the cell components (ion-exchange membrane, electrodes and flow-fields) and operating conditions (flow rate, temperature, vanadium and acid concentration, state of charge (SoC) and cell overpotential) are significant contributors to net transport.

Concentration gradient (diffusion) and electric field (via migration and electro-osmosis) significantly contribute to vanadium and water transport across the ion-exchange membranes. Water transport can also be affected by gradients in osmotic and hydraulic pressure [15]. The most common experimental approach for assessing the concentration-gradient induced crossover is via permeability cells, which has been used by several research groups [16-18]. The effect of various pretreatments of the membrane on the vanadium crossover has been investigated using a permeability cell [19]. Experimental approaches targeting the effect of the electric field on vanadium and water crossover are rare and usually require sophisticated experimental setups $[15,17]$. Therefore, assessing the effect of the electric field on crossover is more frequently studied via numerical modeling approaches $[13,20]$. Darling et al. introduced a new framework for modeling the crossover based on the charge-discharge capacity mismatch and defined the crossover current density using dilute solution theory [21].

It is also important to note that the transport of vanadium species through the ion-exchange membrane is influenced by electrolyte composition; thus, it is SoC dependent $[15,22,23]$. Recently, we reported on the effect of the electric field on vanadium crossover and deduced interaction coefficients for quantifying vanadium crossover as a function of $\mathrm{SoC}$ for Nafion ${ }^{\circledR}$ (DuPont ${ }^{\mathrm{TM}}$, Wilmington, DE, USA) membranes. As a result, the transport parameters for vanadium ions and water, with and without the effect of electric field and as a function of SoC, are now known for Nafion ${ }^{\circledR}$ [15]. It has been shown that the permeability values of vanadium ions with different oxidation states through the ion-exchange membrane are dissimilar, and accordingly, as a function of cycling, vanadium ion accumulation is asymmetric between the negative and positive sides. This asymmetry results in imbalanced vanadium concentration in the negative and positive electrolytes over long-term cycling, causing capacity fade [15]. To understand this behavior, several modeling studies have been developed to simulate vanadium ion and water crossover through Nafion ${ }^{\circledR}$ membranes $[13,14,20,24-29]$. Ultimately, however, more direct experimental tests are needed to confirm and validate any modeling study for these complex solutions and different membranes. 
The ideal membrane should have low ohmic loss, high chemical, mechanical and thermal stability, and superior ionic selectivity. Maintaining high ionic conductivity favors the utilization of thin membranes in order to reduce ohmic overpotential, but necessarily increases diffusive crossover of vanadium ions and water, resulting in increased capacity fade as a function of time and concentration gradient. As a result, selection of an appropriate membrane for VRFB applications is a tradeoff between high ionic conductivity and decreased vanadium ion and water crossover.

Controllable properties of ion-exchange membranes include polymer type (anionic versus cationic), equivalent weight, and membrane reinforcement; the effects of these properties on vanadium ion crossover and capacity decay are of great importance. In addition, the membranes to be used for VRFB applications must meet several transport requirements to ensure economic and technical viability [30]. The incorporation of hydrophobic ionic liquids as membrane dopants has shown promising results for reduced vanadium ion and water crossover [31,32].

Perfluorosulfonic acid-based Nafion ${ }^{\circledR}$ is a commonly-used membrane for VRFB applications. Although Nafion ${ }^{\circledR}$ membranes have high mechanical and chemical stability, they have relatively high material cost and poor ionic selectivity. Considering the overall cost of a VRFB system, the ion-exchange membrane contributes $25 \%-45 \%$ of the total cost depending on energy capacity [33,34]. Furthermore, the overall cost of an ion-exchange membrane is correlated with equivalent weight (EW); thus, lower EWs are preferable from a material cost perspective. However, lower EW decreases the mechanical stability of the membrane among other changes.

The main motivation of the present work is to better understand the effect of equivalent weight and reinforcement on overall cell performance, ionic species crossover, and capacity decay. In this work, we report the results based on VRFB cells that used GORE-SELECT ${ }^{\circledR}$ (Newark, DE, USA) or pure cast film membranes over a range of equivalent weight. Throughout this paper, "GORE-SELECT ${ }^{\circledR \prime \prime}$ is conventionally used to indicate reinforced membranes, except in figures and tables where "GORE-SELECT ${ }^{\circledR}$ " has been used for labeling these types of ion-exchange membranes.

The test matrix includes in situ capacity decay experiments for different cell configurations under constant current density subjected to long-term cycling, polarization curves (obtained to demonstrate the cell voltage as a function of current density), AC impedance tests, ex situ membrane characterization and vanadium crossover tests.

\section{Experimental Section}

\subsection{Membrane Selection and Pretreatment}

The first set of membranes included non-reinforced cation exchange membranes with equivalent weights of 800,950 and $1100 \mathrm{~g} \cdot \mathrm{mol}^{-1}$. The second set of membranes was reinforced cation exchange membranes with the same three equivalent weights as the non-reinforced membranes $(800,950$ and $\left.1100 \mathrm{~g} \cdot \mathrm{mol}^{-1}\right)$. It is important to note that when the ion-exchange membranes are exposed to a solution containing vanadium, sulfuric acid, and water, they physically expand; it is necessary to measure this expansion to calculate accurate diffusive crossover rate constants. The details of such measurements have been provided in Section 4.

\subsection{Method of Approach}

A schematic of the experimental test system used in this work is in Figure 1. The test rig includes four single cells, two-channel peristaltic pumps (Cole Parmer, Masterflex L/S, Vernon Hills, IL, USA) and external reservoirs, as well as ultraviolet/visible (UV-Vis) spectrometers (THORLABS, Newton, NJ, USA) with light sources (Ocean-Optics, Dunedin, FL, USA). Furthermore, a central temperature control unit maintains a constant temperature of $30^{\circ} \mathrm{C}$ for all of the cells and reservoirs. 


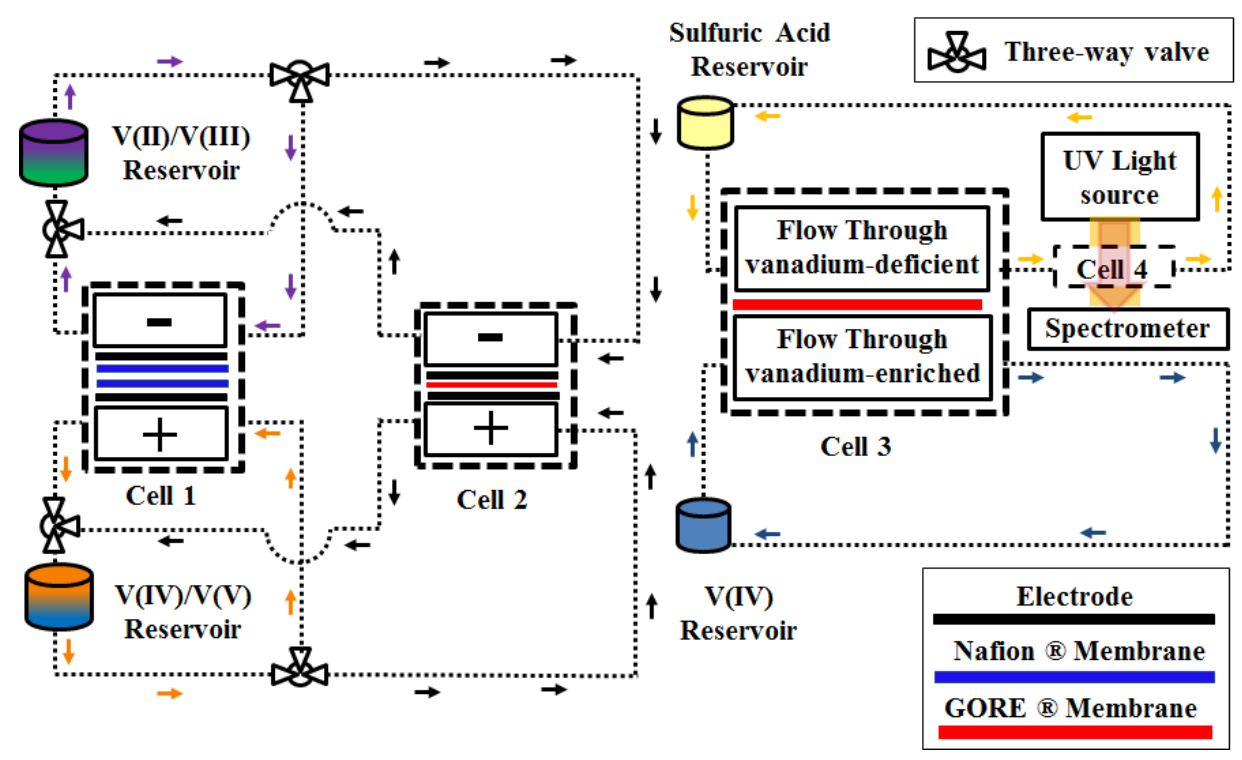

Figure 1. Schematic of the experimental setup.

The initial electrolyte of interest was prepared using Cell 1, which was a $25 \mathrm{~cm}^{2}$ active area cell. Pristine 39AA carbon paper electrodes (SGL Group, Wiesbaden, Germany) were sandwiched between a flow plate and the membranes. Two Nafion 117 membranes were utilized in Cell 1 in order to reduce the rate of crossover during electrolyte preparation. Two electrolyte reservoirs were utilized in conjunction with Cell 1 for $\mathrm{V}(\mathrm{II}) / \mathrm{V}(\mathrm{III})$ and $\mathrm{V}(\mathrm{IV}) / \mathrm{V}(\mathrm{V})$ couples. All reservoirs were sealed and under constant nitrogen purge while stir bars were utilized to ensure uniform composition of the reservoir solutions.

Cell 2 was used to record polarization curves and capacity decay data for the pure cast film and GORE-SELECT ${ }^{\circledR}$ membranes. This cell utilized a $9 \mathrm{~cm}^{2}$ active area with single-path serpentine flow fields and 39AA (pristine, 1 layer) carbon papers as electrodes. Prior to conducting cycling experiments, pristine membranes (pure cast film or GORE-SELECT ${ }^{\circledR}$ membranes) were immersed in a solution of 3.3 M sulfuric acid at room temperature for more than a week. A flow rate of $70 \mathrm{~mL} / \mathrm{min}$ was supplied using a two-channel peristaltic pump. Cycling experiments were conducted at a current density of $100 \mathrm{~mA} / \mathrm{cm}^{2}$ with cut-off voltage limits of $0.2 \mathrm{~V}$ and $1.9 \mathrm{~V}$ for discharge and charge modes, respectively.

In order to assess vanadium transport behavior, we have focused solely on the concentration-gradient induced crossover due to the number of ion-exchange membranes considered in this work. Utilizing concentration-gradient-induced crossover to represent actual crossover is common when many membranes are investigated [19] and/or the current density is low [15,21]. Readers are encouraged to refer elsewhere for a comprehensive analysis of electric-field-induced crossover [15,21].

Cell 3 was designed to investigate the concentration-gradient-induced V(IV) permeability for a series of different membranes. Cell 3 was a two-chamber $9 \mathrm{~cm}^{2}$ active area cell with flow-through flow fields and no electrodes. For Cell 3, the vanadium-enriched solution flowed from the V(IV) reservoir, and vanadium-deficient solution was circulated from the sulfuric acid reservoir and passed through a flow-through UV-Vis measurement unit cell (labeled as Cell 4 in Figure 1) to monitor the vanadium-deficient side's solution in real time. The total time of electrolyte circulation was $24 \mathrm{~h}$. During the circulation of vanadium-enriched and vanadium-deficient electrolytes, concentration gradient-driven crossover occurred from the vanadium-rich electrolyte to the aqueous sulfuric acid solution across the ion-exchange membrane of interest. The vanadium-deficient solution was directed to Cell 4 for real-time monitoring of V(IV) crossover using UV-Vis spectroscopy. To calculate the concentration of $\mathrm{V}(\mathrm{IV})$ on the vanadium-deficient side from the spectroscopic data, the spectra of standardized V(IV) with known concentration were recorded using the same parameters as the experiment. The real-time spectroscopic data were integrated and analyzed with scripts written 
in-house. This experimental procedure was repeated for different configurations of Cell 3 assembled using various pure cast film and GORE-SELECT ${ }^{\circledR}$ membranes.

\subsection{Testing Protocol}

A multichannel potentiostat/galvanostat (Arbin Instruments, College Station, TX, USA) was employed to prepare electrolyte. The initial electrolyte was $1.5 \mathrm{~mol} / \mathrm{L} \mathrm{VOSO}_{4} \cdot x \mathrm{H}_{2} \mathrm{O}$ (Alfa Aesar, Haverhill, MA USA) dissolved in $3.3 \mathrm{~mol} / \mathrm{L}$ sulfuric acid $\left(\mathrm{H}_{2} \mathrm{SO}_{4}\right)$. The initial volume of negative electrolyte was $50 \mathrm{~mL}$, and the positive electrolyte was $100 \mathrm{~mL}$; after initial charging at $1.8 \mathrm{~V}$ until reaching a cut-off current of $4 \mathrm{~mA}, 50 \mathrm{~mL}$ of positive electrolyte were removed to prepare equal volumes of negative and positive electrolyte at near- $100 \% \mathrm{SoC}$. The electrolyte was discharged to $50 \%$ SoC at a constant $100 \mathrm{~mA} / \mathrm{cm}^{2}$ to obtain the condition for polarization curves.

A single-channel Bio-Logic SP240 potentiostat (BioLogic Science Instruments, Seyssinet-Pariset, France) was used to conduct the charge-discharge processes and apply the desired overpotential or current. Cell 2, as shown in Figure 1, was utilized to conduct the polarization and cycling experiments. The cycling experiments were conducted at a constant current of $100 \mathrm{~mA} / \mathrm{cm}^{2}$ for both discharging and charging until reaching cut-off voltages of $0.2 \mathrm{~V}$ and $1.9 \mathrm{~V}$, respectively. AC impedance (at open circuit voltage) data were also obtained using the Bio-Logic SP240 potentiostat.

In order to assess membrane conductivity, Cell 2 was utilized at open-circuit and 50\% SoC conditions using AC impedance. AC impedance experiments were conducted with the positive electrode serving as working electrode and a $5-\mathrm{mV}$ perturbation amplitude; ohmic impedance was taken as the high frequency impedance with no imaginary components (high frequency $x$-axis intercept on a Nyquist plot). To estimate the contact resistance of the other cell components, a cell was assembled without any membrane, and the resistance was found to be $\sim 0.03 \Omega . \mathrm{cm}^{2}$; and this magnitude was subtracted from the total high-frequency impedance to assess the ohmic impedance associated with the membrane.

\subsection{UV-Vis Spectroscopy}

To conduct the vanadium ion permeability tests, Cell 3 and Cell 4 were utilized. Vanadium-enriched solution was circulated in one side of Cell 3, while vanadium-deficient solution was circulated in the other side; the vanadium-deficient solution was directed to Cell 4 after leaving Cell 3 (refer to Figure 1). Therefore, two sets of electrolytes were prepared: one set for the vanadium-enriched side and one set for the vanadium-deficient side. For the vanadium-enriched side, the electrolyte was $1.5 \mathrm{~mol} / \mathrm{L}$ $\mathrm{VOSO}_{4} \cdot x \mathrm{H}_{2} \mathrm{O}$ (Alfa Aesar, Haverhill, MA, USA) dissolved in $3.3 \mathrm{~mol} / \mathrm{L}$ sulfuric acid $\left(\mathrm{H}_{2} \mathrm{SO}_{4}\right)$.

To conduct the $\mathrm{V}(\mathrm{IV})$ permeability measurements, it is necessary to minimize water transport across the membrane so that $\mathrm{V}(\mathrm{IV})$ permeability is only a function of its concentration gradient. To this end, the undesired driving forces of water transport (combined effects of osmotic and hydraulic pressure gradients) need to be balanced. Utilizing the symmetric configuration for Cell 3 (vanadium-deficient side versus vanadium-enriched side) prevents any hydraulic pressure gradient across the membrane. However, the osmotic pressure gradient must also be minimized. In order to balance osmotic pressure, multiple approaches have been described in the literature including matching sulfate concentration on both sides $[15,17]$ or providing a counter cation on the vanadium-deficient side [35]. The use of a counter ion in the vanadium-deficient side introduces new complications to transport measurement and is not used in this work. Only sulfuric acid solution can be used in the vanadium-deficient side if the concentration of the sulfuric acid is chosen based on the procedure explained in our previous work [15]. Therefore, for the vanadium-deficient side, the sulfuric acid concentration was $4.8 \mathrm{M}$, resulting in a zero osmotic pressure gradient for the solvent across the membrane. The volumes of the vanadium-enriched and vanadium-deficient reservoirs were selected to be 200 and $80 \mathrm{~mL}$, respectively.

The electrolytes used for VRFBs exhibit strong visible light absorbance. Therefore, UV-Vis spectroscopy can be utilized to assess the composition of the solution. In this work, the spectrophotometric 
measurements were made using spectrometers in a transmission configuration with a spectral range from 400 to $900 \mathrm{~nm}$. Since the focus of this work is to assess the permeability of V(IV), electrolyte absorbance was measured at a 760-nm wavelength [15]. Such measurements allowed the application of the Beer-Lambert law to determine the relative concentration of V(IV) [15]. To obtain the spectra associated with the vanadium-deficient solution, real-time spectrophotometry was performed while the solution of the vanadium-deficient side was circulating through Cell 4, as shown in Figure S1 (see Supplemental Figure S1).

\section{Vanadium Ion Permeability Assessment}

To obtain the transport parameters for the different types of membranes, permeability values for V(IV) must be determined under a concentration gradient; based on that value, diffusive transport parameters for the particular membrane are formulated according to the procedure explained elsewhere [15]. Concentration gradient-driven crossover occurs from the vanadium-enriched side to the vanadium-deficient side across the membrane. The concentration of diffused vanadium ions is used to obtain the permeability values for a particular membrane [15,17]. The concentration of diffused $\mathrm{V}(\mathrm{IV})$ ions in the vanadium-deficient side can be described using the following equation.

$$
V_{v \_d} \frac{d C_{v \_d}(t)}{d t}=P_{V(I V)}^{m} \frac{A}{t_{m}}\left[C_{v_{-} e}-C_{v_{-} d}(t)\right]
$$

In Equation (5), $V_{v_{-} d}$ represents the volume of the vanadium-deficient electrolyte reservoir; $C_{v_{-} d}$ is the concentration of the vanadium ion in vanadium-deficient electrolyte; $C_{v_{-} e}$ is the concentration of the vanadium ion of vanadium-enriched solution; $A$ is the active area of the membrane in contact with solution; $t_{m}$ represents the thickness of the membrane (after equilibration with electrolyte); and $P_{V(I V)}^{m}$ is the permeability of the V(IV) through the membrane of interest. In Equation (5), the concentration of vanadium in the vanadium-enriched solution is assumed to be constant over the course of each vanadium permeability experiment $(24 \mathrm{~h})$, since the vanadium-enriched reservoir is relatively large compared to the vanadium-deficient reservoir. To calculate permeability values, Equation (6) can be integrated.

$$
\begin{aligned}
\int_{0}^{C_{v_{-} d}} \frac{d\left(C_{v_{-} e}-C_{v_{-} d}(t)\right)}{\left(C_{v_{-} e}-C_{v_{-} d}(t)\right)} & =-\int_{0}^{t} \frac{P_{V(I V)}^{m} A}{V_{v_{-} d} t_{m}} d t \\
\ln \left(\frac{C_{v_{-} e}}{C_{v_{-} e}-C_{v_{-} d}(t)}\right) & =\frac{P_{V(I V)}^{m} A}{V_{v_{-} d} t_{m}} t
\end{aligned}
$$

According to Equation (7), the trend of the left side of the equation versus time can be used to obtain the permeability. After obtaining the permeability values, diffusive transport parameters can be calculated based on Equation (8).

$$
\Lambda_{V(I V)}^{m}=\frac{P_{V(I V)}^{m}}{t_{m}}
$$

In Equation (8), $\Lambda_{V(I V)}^{m}$ represents the $\mathrm{V}(\mathrm{IV})$ diffusive transport parameter.

\section{Results}

\subsection{Capacity Decay during Long-Term Cycling}

Figure 2a includes the discharge capacity as a function of cycle number for the first 30 cycles for different pure cast film and GORE-SELECT ${ }^{\circledR}$ membranes. In Figure $2 a$, the capacity decay data for the pure cast membrane with EW800 has only been reported for the first 15 cycles since the cell capacity became unstable due to membrane degradation. Figure $2 \mathrm{~b}$ shows the theoretical capacity utilization for different membranes over the same duration. It is important to note that the theoretical capacity is determined using Cell 1 (from Figure 1) while charging the initial electrolyte; half of the total charge 
transferred to the electrolyte during the initial charge is evaluated as the theoretical capacity. Since both electrolytes were similar $\left(1.5 \mathrm{~mol} / \mathrm{L} \mathrm{V}(\mathrm{IV})\right.$ as $\mathrm{VOSO}_{4} \cdot x \mathrm{H}_{2} \mathrm{O}$ (Alfa Aesar) dissolved in $3.3 \mathrm{~mol} / \mathrm{L} \mathrm{H}_{2} \mathrm{SO}_{4}$ ), half of the total initial charge corresponds to the full capacity window for an operating VRFB.

As shown in Figure 2a,b, the capacity and theoretical capacity utilization both decrease during cycling. The theoretical capacity utilization is an important metric for assessing overall vanadium ion utilization within a VRFB cell. Due to imposing voltage limits while maintaining cycling current (in this work, $0.2 \mathrm{~V}$ and $1.9 \mathrm{~V}$ ), the theoretical capacity utilization is always lower than $100 \%$ since the total content of all dissolved vanadium ions cannot be utilized. The properties of the ion-exchange membrane directly affect the theoretical capacity utilization through the crossover rate. A higher rate of crossover decreases the open-circuit voltage (OCV) of the cell and consequently results in reaching the voltage limits sooner during a cycle, all other contributing parameters being equal. The theoretical discussion of such an effect is the focus of a previous publication [27]. According to Figure 2b, at the end of 30 cycles, the reinforced/EW1100 exhibits the highest magnitude of theoretical capacity utilization of $\sim 64 \%$, and the non-reinforced/EW800 shows the lowest theoretical capacity utilization ( $~ 59 \%$, at the end of just 15 cycles). Furthermore, as seen in Figure $2 b$, increased equivalent weight results in increased theoretical capacity utilization for both reinforced and non-reinforced membranes. Comparing similar equivalent weights of non-reinforced and reinforced membranes, reinforcement increases the theoretical capacity utilization. For example, the EW1100 membrane showed 2\% greater capacity utilization resulting from reinforcement; for the EW950 membrane, reinforcement increases the theoretical capacity utilization by $3 \%$ at the end of 30 cycles compared to non-reinforced.

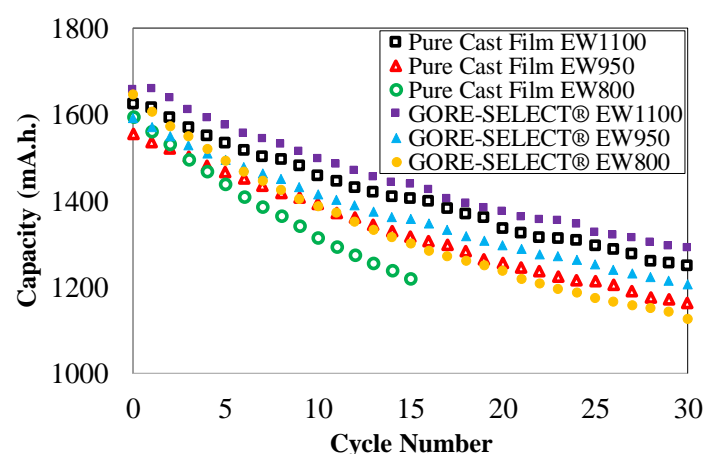

(a)

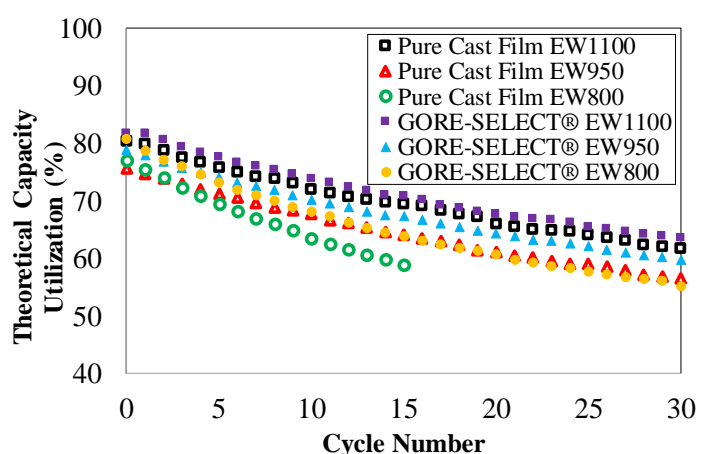

(b)

Figure 2. (a) Capacity decay as a function of cycle number; (b) theoretical capacity utilization as a function of cycle number. EW, equivalent weight.

Figure 3 includes the discharge capacity decay for different membranes as a function of cycle number and as a function of time. Here, the capacity decay is defined as the ratio of the decrease in discharge capacity to the initial discharge capacity of the battery.

According to Figure 3a, the reinforced EW1100 membrane exhibits the lowest rate of capacity decay ( $22 \%$ at the end of 30 cycles), and non-reinforced EW800 shows the highest rate of capacity decay ( $24 \%$ at the end of just 15 cycles). It is important to note that, although the number of cycles for all of the experimental membranes was 30 (except non-reinforced EW800), the total cycling time for the different configurations varied due to different ohmic overpotentials imposed as a function of membrane conductivity. However, in general, cycling experiments were conducted over the course of approximately $100 \mathrm{~h}$. Similar to Figure 3a, the reinforced membrane with EW1100 exhibits the lowest rate of capacity decay $(\sim 22 \%$ at the end of $\sim 100 \mathrm{~h})$, and non-reinforced EW800 results in the highest rate of capacity decay $(\sim 24 \%$ at the end of $\sim 59 \mathrm{~h})$ as a function of time.

According to Figure 3, increased equivalent weight mitigates capacity decay for both non-reinforced and reinforced membranes. As shown in Figure 3, increasing the equivalent weight from 950 to $1100 \mathrm{~g} \cdot \mathrm{mol}^{-1}$ decreases the capacity decay by $\sim 3 \%$ at the end of 30 cycles. The effect 
on capacity decay is more pronounced when increasing equivalent weight from 800 to $950 \mathrm{~g} \cdot \mathrm{mol}^{-1}$ for reinforced membranes in which the capacity decay decreased by $7 \%$ at the end of 30 cycles. Furthermore, it can be observed from Figure 3 that reinforcement decreases the capacity decay for identical EW membranes. Comparing the non-reinforced and reinforced membranes, for the case of EW1100 and EW950, reinforcement decreased the capacity decay by $1.5 \%$ at the end of 30 cycles.

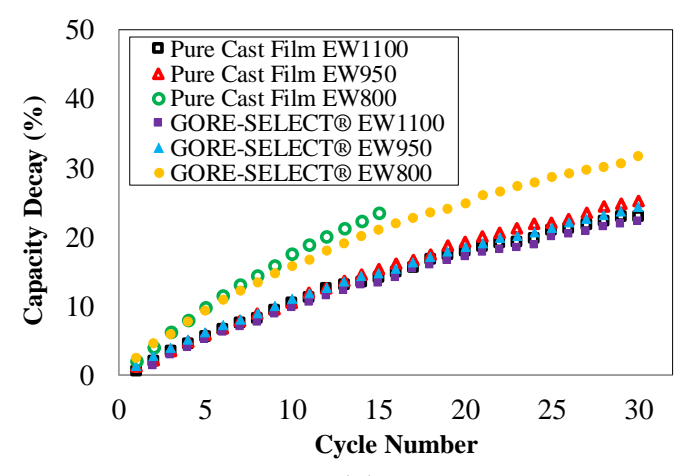

(a)

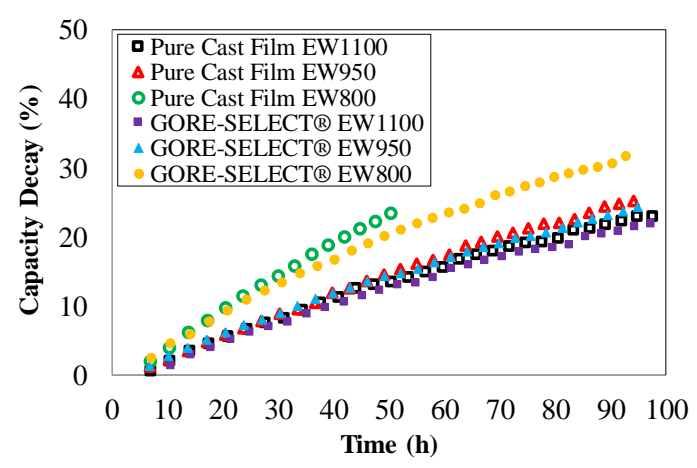

(b)

Figure 3. Capacity decay for different ion-exchange membranes as a function of (a) cycle number and (b) time.

The observed differences in capacity decay are primarily due to vanadium crossover since the other components (electrodes, flow fields and electrolyte) were kept consistent. Figure 4a includes coulombic efficiency for the membranes in this work. The coulombic efficiency was calculated here as the ratio of discharge capacity over charge capacity at $100 \mathrm{~mA} / \mathrm{cm}^{2}$. The coulombic efficiency for all membranes tested in this work exceeded $95 \%$. Figure $4 \mathrm{~b}$ shows the voltage efficiency for the membranes over a range of current density. Voltage efficiency is defined here as the ratio of average discharging voltage over the average charging voltage up to $150 \mathrm{~mA} / \mathrm{cm}^{2}$. As shown in Figure $4 \mathrm{~b}$, increasing the current density decreases the voltage efficiency for all experiments; voltage efficiencies exceeded $75 \%$ at $150 \mathrm{~mA} / \mathrm{cm}^{2}$. Figure $4 \mathrm{c}$ shows polarization curve results at $50 \%$ SoC for cells based on each membrane. Figure $4 \mathrm{~d}$ includes power density data for membranes as a function of current density for discharging conditions. As shown, a power density of $181-190 \mathrm{~mW} / \mathrm{cm}^{2}$ was achieved at a discharge current density of $150 \mathrm{~mA} / \mathrm{cm}^{2}$. Furthermore, it is important to note for clarity that the polarization curves and power density curves are shown just for discharge conditions since the charge and discharge cases were nearly symmetric.

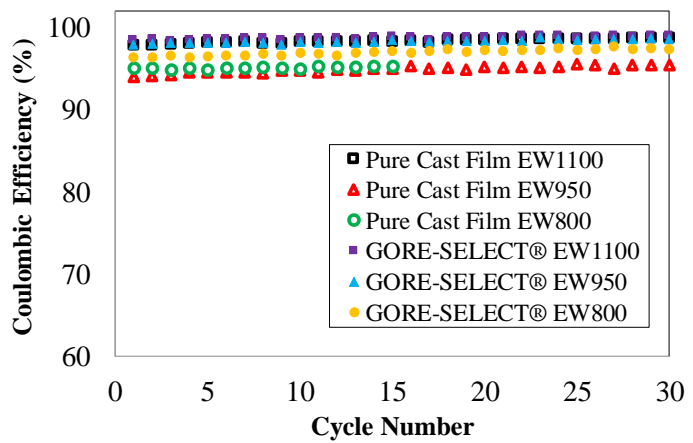

(a)

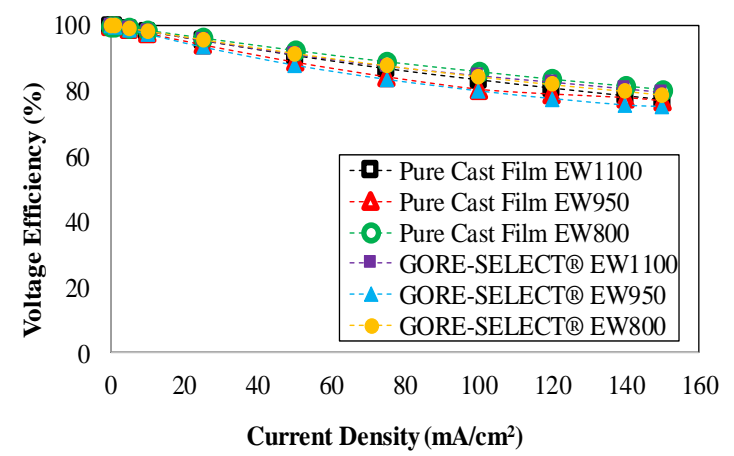

(b)

Figure 4. Cont. 


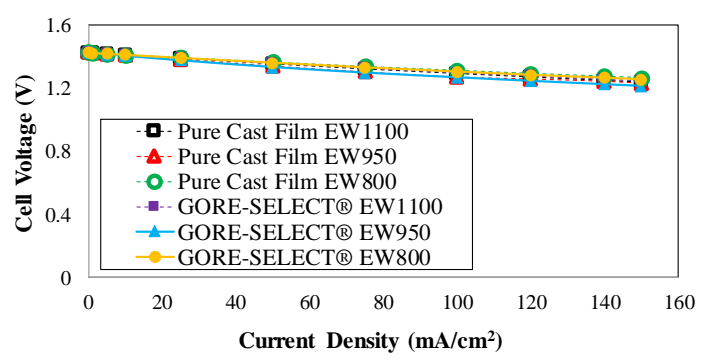

(c)

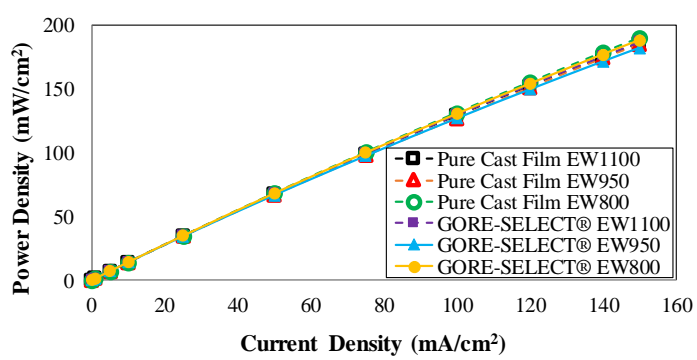

(d)

Figure 4. Characteristic plots for the experimental membranes: (a) coulombic efficiency, (b) voltage efficiency, (c) polarization curves and (d) power density.

It is important to note that, according to Figure 4a, coulombic efficiency for different membranes does not exhibit a direct correlation to increased equivalent weight or the addition of membrane reinforcement. The primary reason for such a trend lies in the definition of coulombic efficiency for VRFB systems. Coulombic efficiency is defined as the ratio of the discharge capacity over charge capacity [36]; therefore, for a membrane, both of these quantities can be small compared to the theoretical capacity while the cell still achieves high coulombic efficiency. Therefore, comparing Figure 4a with Figure 3, capacity fade as a function of cycle number or/and capacity decay as a function of time is a better metric to assess the viability of a particular membrane. Such a metric better represents superior ionic selectivity and the reduction of the vanadium crossover rate.

According to Figure 4, voltage efficiency and polarization curves do not show a linear correlation to either increased equivalent weight and/or membrane reinforcement. An ideal ion-exchange membrane would decrease vanadium ion crossover and ohmic overpotential simultaneously. However, if the reduction of vanadium ion crossover via use of a particular membrane is obtained at the cost of increased ohmic overpotential, the polarization curves and voltage efficiency (consequently the power density) show a negative impact, as evidenced by Figure $4 \mathrm{~b}-\mathrm{d}$. This observation has been further clarified through measuring area-specific resistance (ASR) associated with each membrane.

Table 1 includes pre- and post-cycling ASR values for each pair of membranes at $100 \mathrm{~mA} \cdot \mathrm{cm}^{2}$ (see Supplemental Figure S2). For all experimental membranes, the ASR value increased during cycling $(\sim 9 \%-18 \%)$. For non-reinforced and reinforced membranes, increasing the equivalent weight yielded increased ASR: increasing equivalent weight from 800 to $950 \mathrm{~g} \cdot \mathrm{mol}^{-1}$ increased the ASR by $36 \%$, and increasing the equivalent weight from 950 to $1100 \mathrm{~g} \cdot \mathrm{mol}^{-1}$ increased the ASR by another $\sim 16 \%$. Considering the reinforced membranes, increasing the equivalent weight from 800 to $950 \mathrm{~g} \cdot \mathrm{mol}^{-1}$ increased the ASR by $\sim 43 \%$, while increasing the equivalent weight from 950 to $1100 \mathrm{~g} \cdot \mathrm{mol}^{-1}$ increased the ASR by a similar $\sim 16 \%$.

Table 1. Initial and increase in area-specific resistance (ASR) and ohmic overpotential (at $100 \mathrm{~mA} \cdot \mathrm{cm}^{-2}$ ) as a function of cycling for different membranes.

\begin{tabular}{|c|c|c|c|c|}
\hline Membrane Type & $\begin{array}{c}\text { Initial ASR } \\
\left(\Omega \cdot \mathrm{cm}^{2}\right)\end{array}$ & $\begin{array}{l}\text { Relative Increase } \\
\text { in ASR (\%) }\end{array}$ & $\begin{array}{c}\text { Initial Ohmic } \\
\text { Overpotential at } \\
100 \mathrm{~mA} \cdot \mathrm{cm}^{-2}(\mathrm{mV})\end{array}$ & $\begin{array}{c}\text { Increase in Ohmic } \\
\text { Overpotential at } 100 \mathrm{~mA} \cdot \mathrm{cm}^{-2} \\
\text { during } 30 \text { Cycles }(\mathrm{mV})\end{array}$ \\
\hline Pure Cast Film EW1100 & 0.240 & 14.17 & 24.0 & 3.41 \\
\hline Pure Cast Film EW950 & 0.206 & 14.08 & 20.6 & 2.94 \\
\hline Pure Cast Film EW800 & 0.151 & 17.88 & 15.1 & 2.74 \\
\hline GORE-SELECT $^{\circledR}$ EW1100 $^{2}$ & 0.282 & 16.67 & 28.2 & 4.66 \\
\hline GORE-SELECT ${ }^{\circledR}$ EW950 & 0.244 & 12.70 & 24.4 & 3.11 \\
\hline GORE-SELECT ${ }^{\circledR}$ EW800 & 0.171 & 16.96 & 17.1 & 2.93 \\
\hline
\end{tabular}


Furthermore, across all equivalent weights, reinforcement increased the ASR. Comparing the non-reinforced with reinforced membranes, for the EW1100 and EW950 sets, the ASR increases by 18\% due to membrane reinforcement, and for the EW800 pair, the increase in ASR is $~ 13 \%$. In summary, the non-reinforced EW800 exhibits the lowest $\left(0.15 \Omega \cdot \mathrm{cm}^{2}\right)$ and the reinforced EW1100 results in the highest value $\left(0.28 \Omega \cdot \mathrm{cm}^{2}\right)$ of ASR.

A comparison of results in Table 1 and Figure 3 reveals that both of these membrane modification techniques (reinforcement and increased equivalent weight) resulted in decreased capacity decay; therefore, this simultaneous mixed effect is the primary reason for the trend observed for polarization curves, coulombic and voltage efficiencies and the power density graphs shown in Figure 4. This mixed effect has been further clarified in the next section. The increase in ASR during cycling results in an increase in ohmic overpotential as tabulated in Table 1 for the case of constant discharge at $100 \mathrm{~mA} \cdot \mathrm{cm}^{-2}$.

\subsection{Crossover of Vanadium Ions}

The major source for discharge capacity decay during cycling (as shown in Figure 3 ) is the undesired transport of vanadium ions through the ion-exchange membrane. In general, concentration gradient and electric field are the main driving forces for vanadium ion crossover. In this work, we have investigated the crossover of vanadium ions as a function of concentration gradient only. Among vanadium ions, concentration gradient-driven crossover has been assessed via focusing on the transport of V(IV) since the electrolyte preparation does not require any additional charge/discharge processes, ensuring uniform electrolyte composition.

Figure 5 shows the concentration of vanadium V(IV) ion on the vanadium-deficient side over a twenty-four-hour time period; the crossover behavior observed here corresponds to conditions at SoC $=0 \%$ on the positive side. The UV-Vis spectra were recorded at 6-h intervals (five sampling spectra) for each membrane, and the recorded spectra were utilized to calculate the concentrations shown in Figure 5.

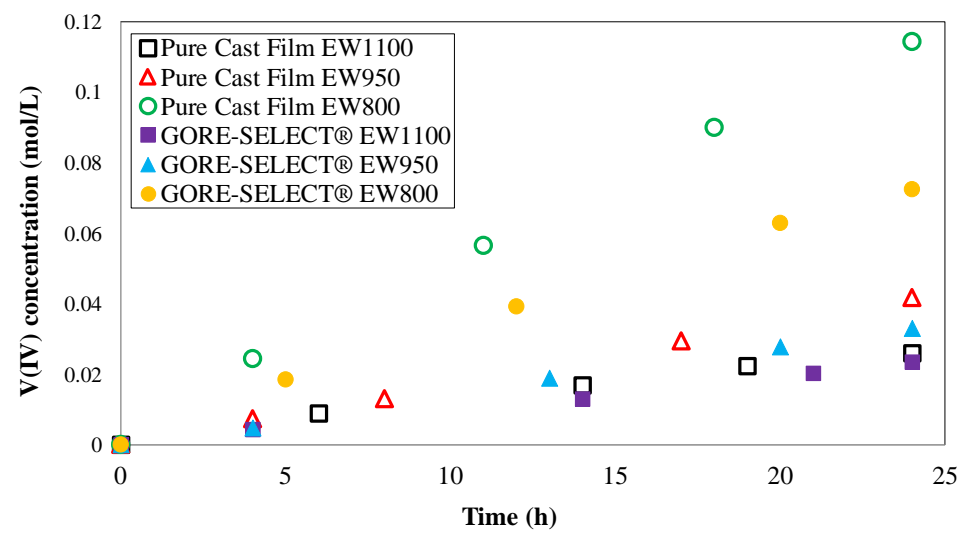

Figure 5. Concentration of diffused vanadium V(IV) ion to the vanadium-deficient chamber within the twenty-four hour time period.

As shown in Figure 5, the concentrations of diffused V(IV) to the vanadium-deficient side differ as a function of membrane composition. The maximum concentration of diffused V(IV) at the end of a 24-h crossover test was measured for the non-reinforced membrane with EW800 $\left(\sim 0.114 \mathrm{~mol} \cdot \mathrm{L}^{-1}\right)$, and the minimum concentration was achieved by reinforced membrane with EW1100 $\left(\sim 0.023 \mathrm{~mol} \cdot \mathrm{L}^{-1}\right)$. The concentration of diffused vanadium V(IV) ions shown in Figure 5 can be used to obtain the permeability values for different membrane morphologies using the slope of a semi-natural log plot, formulated in Equation (7). 
As indicated by Equation (7), the slope of semi-natural log plots (see Supplemental Figure S3) can be used to calculate permeability values; here, it is necessary to incorporate the expanded thickness of the membranes in the modeling framework. To this end, a solution of aqueous sulfuric acid and vanadium (3.3 mol/L acid, $1.5 \mathrm{~mol} / \mathrm{L}$ vanadium (V(III)/V(IV) mix) was prepared, and the membranes were soaked in this solution for more than a week at room temperature. This composition was chosen to reflect the only stable vanadium species that can coexist in the membrane; V(II) and V(V) are expected to react with $\mathrm{V}(\mathrm{III})$ and $\mathrm{V}(\mathrm{IV})$. While the external solution is known to influence membrane properties, it is the internal environment that defines membrane properties. Figure 6 shows the thickness of the membranes measured after soaking in electrolyte. To measure the thickness, three sets of measurements were conducted using a digital micrometer (Mitutoyo, Kawasaki, Japan), and each reported thickness value was the average of all measurements; error bars were calculated based on the deviation of maximum and minimum thickness measurements from the average value.

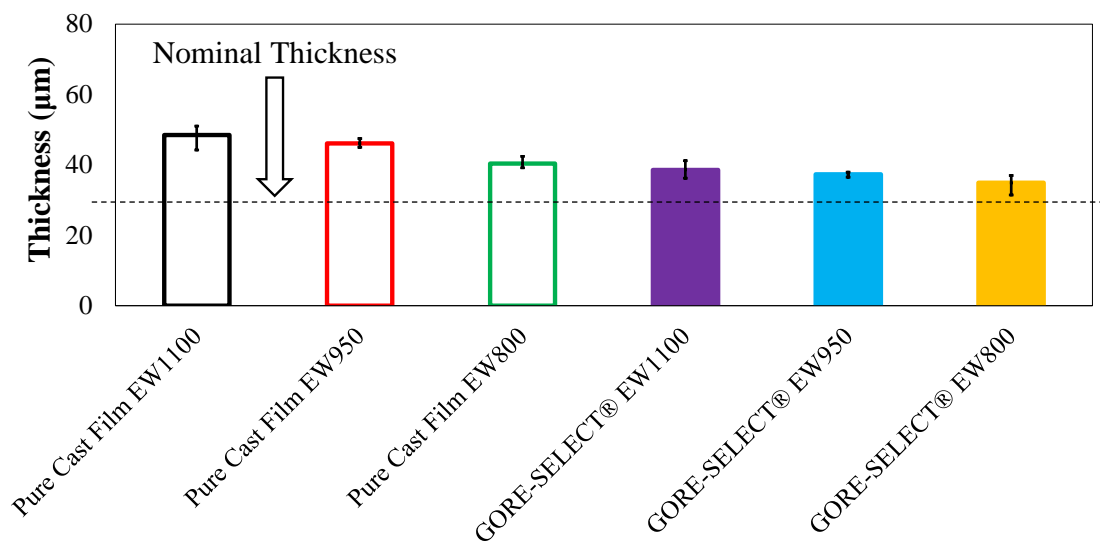

Figure 6. Thickness of the membranes after soaking in the solution of $1.5 \mathrm{~mol} / \mathrm{L} \mathrm{V}(\mathrm{III}) / \mathrm{V}(\mathrm{IV})$ and $3.3 \mathrm{~mol} / \mathrm{L}$ sulfuric acid.

As shown in Figure 6, the nominal thickness for all membranes tested was $30 \mu \mathrm{m}$. However, expansion (degree of swelling) differed significantly as a function of membrane properties. As a general trend, for both non-reinforced and reinforced membranes, the expansion was greater for higher equivalent weights. For example, among the non-reinforced membranes, EW1100 exhibits $\sim 62 \%$ expansion in the through-plane direction, and EW800 shows $\sim 35 \%$. However, the reinforced EW1100 membrane expanded by $\sim 29 \%$, and reinforced EW800 expanded by $\sim 16.5 \%$. As expected, the addition of reinforcement significantly decreases through-plane expansion. The quantitative details of the cation exchange membranes tested in this work are shown in Table 2.

Table 2. The details of the cation exchange membranes utilized in this work.

\begin{tabular}{ccccc}
\hline Membrane Type & $\begin{array}{c}\text { Manufacturing } \\
\text { Details }\end{array}$ & $\begin{array}{c}\text { Nominal } \\
\text { Thickness }(\boldsymbol{\mu m})\end{array}$ & $\begin{array}{c}\text { Average Thickness } \\
\text { after Soak }(\boldsymbol{\mu m})\end{array}$ & $\begin{array}{c}\text { Through-Plane } \\
\text { Swelling }(\mathbf{\%})\end{array}$ \\
\hline Pure Cast Film EW1100 & Cast film & 30 & 49 & 62 \\
\hline Pure Cast Film EW950 & Cast film & 30 & 46 & 54 \\
\hline Pure Cast Film EW800 & Cast film & 30 & 40 & 35 \\
\hline GORE-SELECT $^{\circledR}$ EW1100 & Reinforced & 30 & 39 & 29 \\
\hline GORE-SELECT $^{\circledR}$ EW950 & Reinforced & 30 & 37 & 24 \\
\hline GORE-SELECT $^{\circledR}$ EW800 & Reinforced & 30 & 35 & 16 \\
\hline
\end{tabular}

Figure 7 includes the resultant permeability values, based on the linear fits formulated in Equation (7). It is important to note that, for calculating the permeability values of V(IV) ions for each membrane, 
the thickness of the membranes equilibrated with the aqueous vanadium and sulfuric acid (as tabulated in Table 2) was utilized.

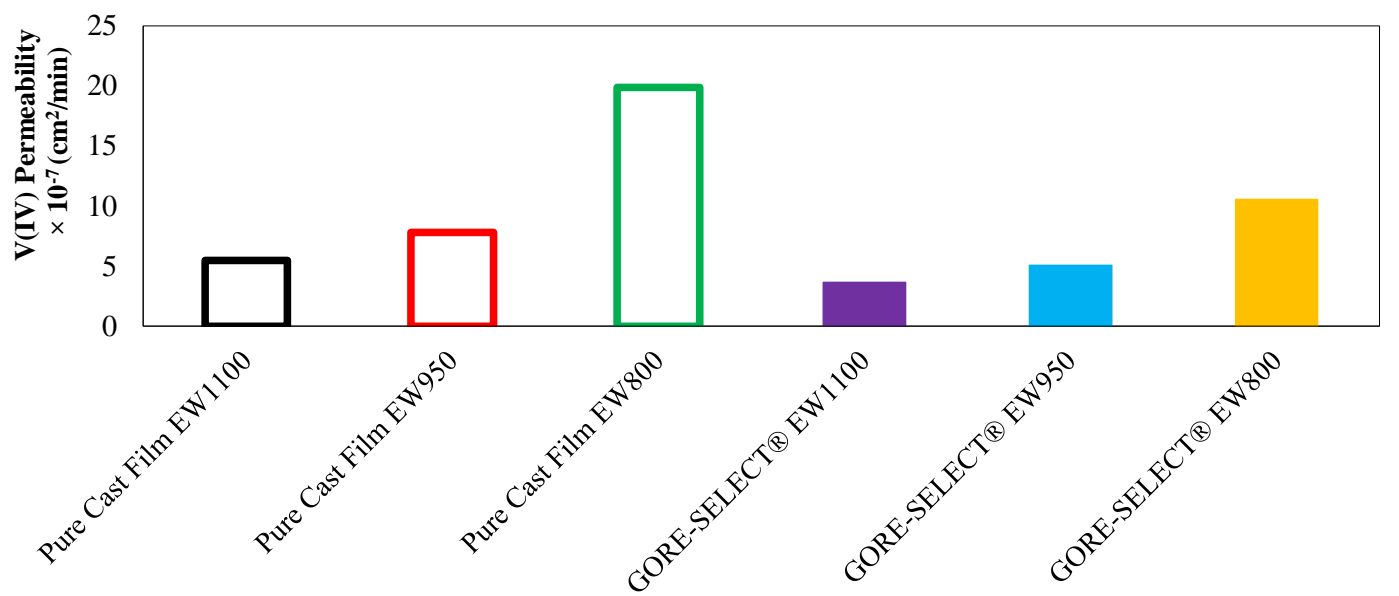

Figure 7. Measured permeability values for different membranes.

According to Figure 7, it is clear that, for both non-reinforced and reinforced membranes, increasing the equivalent weight decreases the V(IV) ion permeability. For non-reinforced membranes, decreasing the equivalent weight from 1100 down to $950 \mathrm{~g} \cdot \mathrm{mol}^{-1}$ increases the $\mathrm{V}(\mathrm{IV})$ permeability by $42 \%$, and further decreasing the equivalent weight to $800 \mathrm{~g} \cdot \mathrm{mol}^{-1}$ results in $155 \%$ greater V(IV) permeability. In comparison, for reinforced membranes, decreasing the equivalent weight from 1100 down to $950 \mathrm{~g} \cdot \mathrm{mol}^{-1}$ increases the $\mathrm{V}(\mathrm{IV})$ permeability by $39 \%$, and further decreasing the equivalent weight to $800 \mathrm{~g} \cdot \mathrm{mol}^{-1}$ further increases the V(IV) permeability by $109 \%$.

Table 3 includes the numerical values of V(IV) permeability for each ion-exchange membrane, as well as the diffusive transport parameter, which has been formulated based on Equation (8). The diffusive transport parameter is utilized to calculate the concentration-gradient-induced crossover flux according to the mathematical formulation provided in our previous publication [15].

Table 3. The vanadium V(IV) ion transport parameters through various ion-exchange.

\begin{tabular}{ccc}
\hline Membrane Type & $\boldsymbol{P}_{V(I V)}^{m}\left(\mathbf{c m}^{\mathbf{2}} \cdot \mathbf{m i n}^{-\mathbf{1}} \times \mathbf{1 0}^{-\mathbf{7}}\right)$ & $\boldsymbol{\Lambda}_{V(I V)}^{m}\left(\mathbf{c m} \cdot \mathbf{m i n}^{-\mathbf{1}} \times \mathbf{1 0}^{-\mathbf{7}}\right)$ \\
\hline Pure Cast Film EW1100 & 5.49 & 1131 \\
Pure Cast Film EW950 & 7.80 & 1689 \\
Pure Cast Film EW800 & 19.87 & 4919 \\
GORE-SELECT $^{\circledR}$ EW1100 & 3.66 & 948 \\
GORE-SELECT $^{\circledR}$ EW950 & 5.08 & 1361 \\
GORE-SELECT $^{\circledR}$ EW800 & 10.59 & 3029 \\
\hline
\end{tabular}

It is also important to quantify the effect of reinforcement on the reduction of V(IV) permeability. Figure 8 is a plot of $\mathrm{V}(\mathrm{IV})$ ion permeability and ASR as a function of equivalent weight. When comparing similar equivalent weights, reinforcement decreases the V(IV) permeability for all three compositions considered in this work. However, the effect is not linear. As shown in Figure 8, the observed trend for the ASR is the opposite of V(IV) permeability and exhibits an increase as a function of increased equivalent weight and reinforcement.

For the EW800 membranes, reinforcement decreased the V(IV) permeability by 47\%; for EW 950 , reinforcement decreased the V(IV) permeability by $\sim 35 \%$; and for EW1100, the reduction of V(IV) permeability as a function of membrane reinforcement was $\sim 33 \%$.

As discussed earlier, the primary reason for capacity fade as a function of cycling was assumed to be the crossover of vanadium ions. Therefore, to validate this assumption, it is critical to investigate 
any correlation between the discharge capacity decay and the V(IV) ion permeability values. As shown in Figure 3, the discharge capacity of cells with different configurations decreased as a result of cycling regardless of the type of membrane, but with different rates. No contribution is expected from side reactions since the voltage limits avoided their onset and also due to the lack of observed gas generation. In addition, component degradation should be negligible or consistent since all tests were conducted under identical conditions. Thus, the crossover of vanadium ions should be the primary driver of capacity fade.

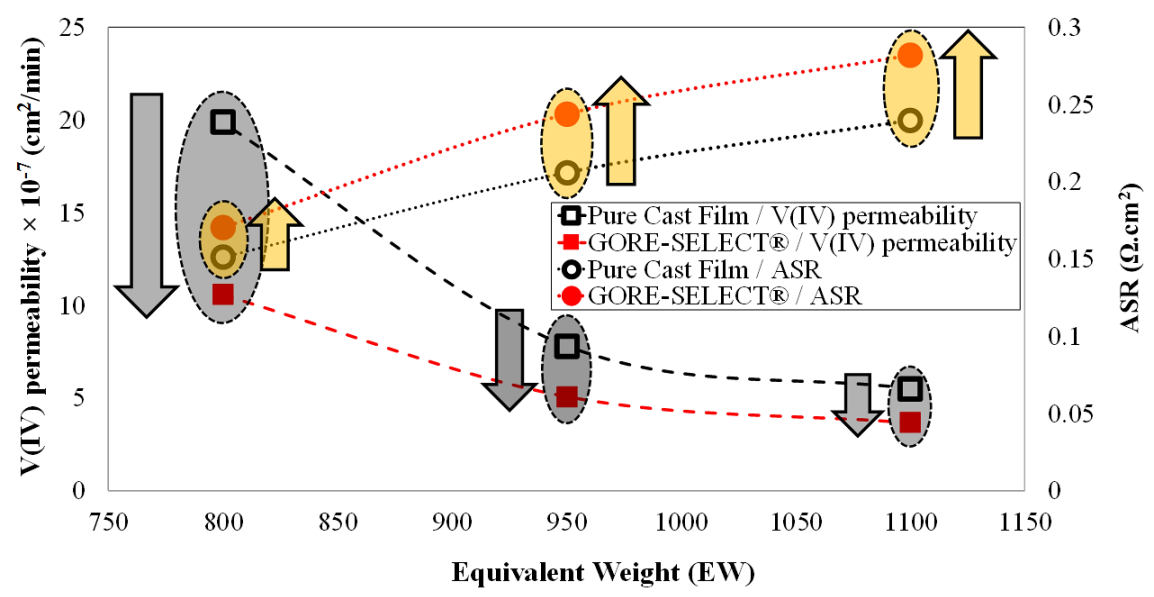

Figure 8. Correlation between equivalent weight with V(IV) permeability and ASR.

Figure 9 includes the discharge capacity decay at the end of 30 cycles (or approximately $90 \mathrm{~h}$ ) for non-reinforced and reinforced membranes as a function of vanadium V(IV) permeability. In Figure 9, the discharge capacity decay data associated with non-reinforced EW800 have been extrapolated since the cycling test for this membrane was only conducted for the first 15 cycles.

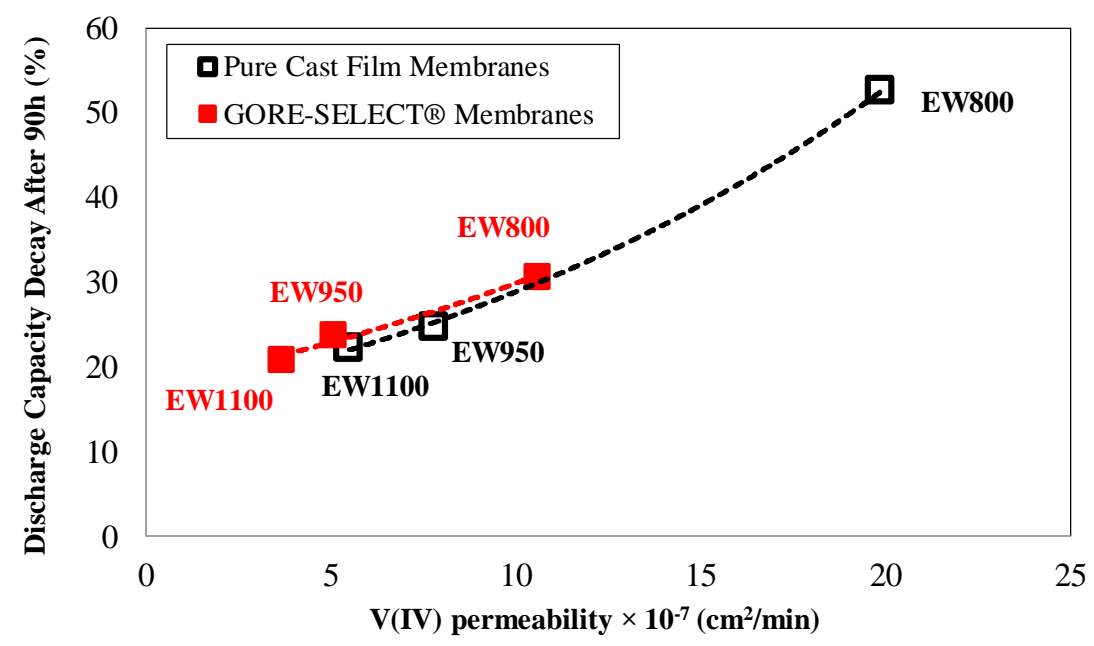

Figure 9. The discharge capacity decay at the end of cycling as function of vanadium V(IV) permeability.

As is evident in Figure 9, there exists a strong correlation between the discharge capacity decay at the end of cycling with V(IV) permeability values. According to Figure 9, for non-reinforced membranes, increasing the equivalent weight from 800 to $950 \mathrm{~g} \cdot \mathrm{mol}^{-1}$, decreases the discharge capacity decay (after $90 \mathrm{~h}$ ) from $53 \%-25 \%$ while decreasing the V(IV) permeability by $61 \%$, and further increasing the equivalent weight to $1100 \mathrm{~g} \cdot \mathrm{mol}^{-1}$ decreases the discharge capacity decay to $22 \%$, while the $\mathrm{V}(\mathrm{IV})$ permeability decreases by $30 \%$. 
A similar trend was observed for reinforced membranes: increasing the equivalent weight from 800 to $950 \mathrm{~g} \cdot \mathrm{mol}^{-1}$ decreases the discharge capacity decay from $31 \%$ down to $24 \%$, while decreasing the $\mathrm{V}(\mathrm{IV})$ permeability by $52 \%$; further increasing the equivalent weight from 950 to $1100 \mathrm{~g} \cdot \mathrm{mol}^{-1}$ decreases the discharge capacity decay to $21 \%$, while decreasing the V(IV) permeability by $28 \%$.

Finally, it is important to quantify vanadium crossover as a function of membrane thickness. As shown in Figure 6, the ion-exchange membranes selected for this work all had a nominal thickness of $30 \mu \mathrm{m}$; however, when soaked in a solution of aqueous sulfuric acid and vanadium, they swelled as a function of membrane reinforcement and equivalent weight. Given the permeability and swelling responses to EW, the following figure compares vanadium ion permeability (V(IV)) as a function of through-plane membrane swelling.

As shown in Figure 10, V(IV) permeability decreases for both the pure cast film and GORE-SELECT $^{\circledR}$ membranes as a function of increased through-plane membrane swelling. As tabulated in Table 2, increased equivalent weight increases through-plane swelling, and this results in reduced permeability for V(IV) ion. Therefore, an inverse correlation exists between swelling and permeability for pure cast film and GORE-SELECT ${ }^{\circledR}$ membranes. The likely cause of this relationship is greater membrane thickness impeding V(IV) crossover.

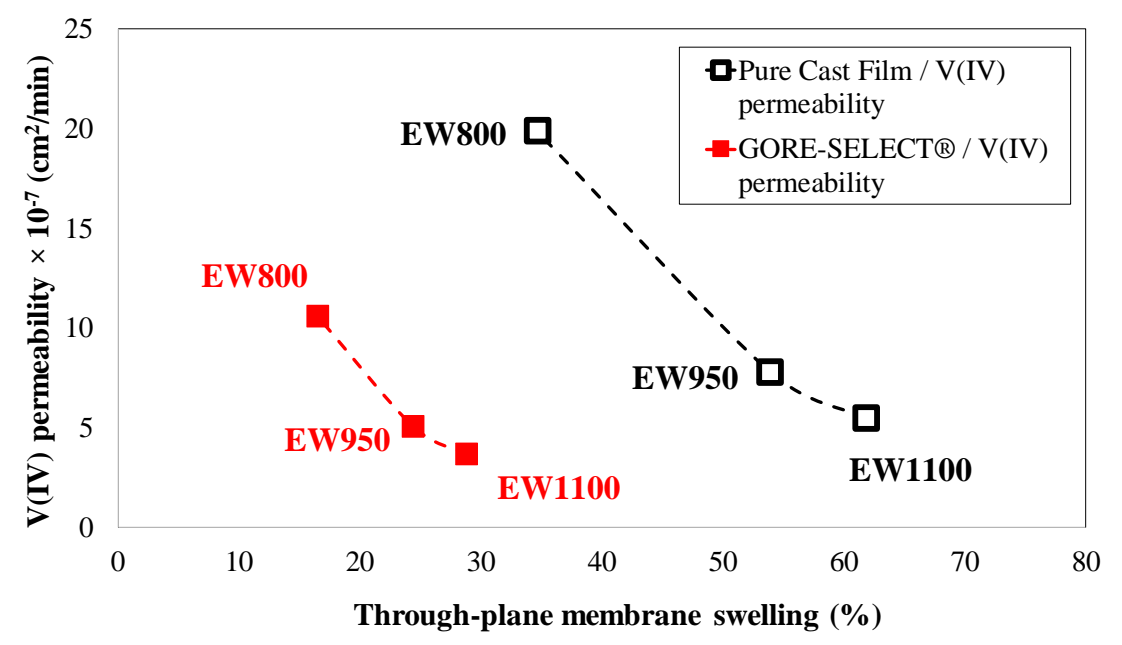

Figure 10. Correlation between V(IV) permeability and through-plane membrane swelling.

A physicochemical description of the two distinct trends observed in Figure 8 is also of interest. First, as shown in Figure 8, increased equivalent weight results in decreased V(IV) permeability for both pure cast film and reinforced membranes. A macroscopic mathematical model based on conservation of mass, charge, momentum, and energy along with a meso-scale model based on dissipative particle dynamics (DPD) has previously been used to assess vanadium ion crossover behavior due to a concentration gradient [15,37]. Based on the macroscopic model of vanadium ion transport through polymeric membranes, vanadium crossover under the concentration gradient can be best described by the diffusive transport parameter [15]. As included in Table 3, the diffusive transport parameter decreases with increased equivalent weight. With a concentration-gradient-induced driving force for vanadium ion crossover, increased equivalent weight results in greater membrane swelling (as shown in Figure 6), resulting in higher diffusion resistance via increased path-length for the transport of vanadium ions; accordingly, the diffusive transport parameter is decreased. A meso-scale model description of vanadium ion transport has also been formulated by others based on DPD simulations, and it shows that increasing equivalent weight results in a stronger vanadium-sulfonate bond and accordingly more structured configuration. The stronger anion-cation interaction (V(IV) and sulfonate) as a function of increased equivalent weight, thus results in decreased diffusivity of vanadium ions [37]. 
As shown in Figure 8, membrane reinforcement results in decreased vanadium ion permeability for all equivalent weights. This observation is likely due to water transport behavior through the membranes; advection of vanadium ions through the membrane is influenced by water transport. It is well-established that water permeability through the membranes is both in equilibrium (solubility) and non-equilibrium (diffusivity) and is a strong function of the porous structure of the membrane [38-41]. Water transport has two distinct steps including surface adsorption (permeation through the surface) and internal absorption and transport across the membrane (diffusion); accordingly, the water transport rate is governed by water uptake and release rates [40]. The implementation of reinforcement decreases vanadium ion permeability by acting as a molecular sieve in the porous structure of the membrane [39]. The porous structure of the reinforced layer allows for the transport of water molecules while decreasing the transport of vanadium ions (V(IV)) by size exclusion. Accordingly, the contribution of vanadium ion transport via advection increases with decreased equivalent weight. Therefore, as shown in Figure 8, the inclusion of reinforcement results in a sharper decrease in vanadium permeability for lower equivalent weight membranes.

\section{Summary and Conclusions}

In this work, the effects of equivalent weight and membrane reinforcement on capacity fade and crossover in a VRFB system have been experimentally investigated. Three equivalent weights $\left(800,950\right.$ and $\left.1100 \mathrm{~g} \cdot \mathrm{mol}^{-1}\right)$ were considered for non-reinforced and reinforced membranes.

It is shown that vanadium crossover in VRFB systems can be mitigated either by increasing the ion-exchange membrane's equivalent weight or implementing reinforcement. However, there is a tradeoff between decreasing capacity decay and increasing area-specific resistance (ASR), though this tradeoff is strongly dependent on equivalent weight. For non-reinforced membranes, increasing the equivalent weight (EW) from 950 to $1100 \mathrm{~g} \cdot \mathrm{mol}^{-1}$ decreases the $\mathrm{V}(\mathrm{IV})$ permeability by $\sim 30 \%$, but increases the area-specific resistance (ASR) by $\sim 16 \%$. Furthermore, increasing the equivalent weight from 800 to $950 \mathrm{~g} \cdot \mathrm{mol}^{-1}$ decreases the V(IV) permeability by $\sim 61 \%$, but increases the ASR by $\sim 36 \%$. Comparing the non-reinforced with reinforced membranes, for the EW1100 and EW950 membrane, the ASR increases by $\sim 18 \%$ due to membrane reinforcement; but reinforcement decreases the V(IV) permeability by 35\% for EW950 membranes and by 33\% for EW1100 membranes. However, for the EW800 membranes, reinforcement decreases the V(IV) permeability by $\sim 47 \%$, but increases the ASR by $\sim 13 \%$.

Furthermore, it was shown that there exists a direct correlation between the discharge capacity decay over long-term cycling with V(IV) permeability values, confirming that the main contributor to capacity fade during cycling is due to vanadium crossover. As an example, for non-reinforced membranes, increasing the equivalent weight from 800 to $950 \mathrm{~g} \cdot \mathrm{mol}^{-1}$, decreases the discharge capacity decay at the end of cycling by $\sim 53 \%$ and V(IV) permeability by $\sim 61 \%$. For reinforced membranes, increasing the equivalent weight from 800 to $950 \mathrm{~g} \cdot \mathrm{mol}^{-1}$ decreases the discharge capacity decay at the end of cycling by $\sim 23 \%$ and $V(I V)$ permeability by $\sim 52 \%$. This implies that $V(I V)$ crossover tests can be utilized to assess the viability of a particular membrane of interest for long-term VRFB applications.

Finally, increased equivalent weight of the ion-exchange membrane decreases vanadium permeability, resulting in decreased capacity fade over cycling. When the membranes (pure cast film and GORE-SELECT ${ }^{\circledR}$ membranes) are exposed to aqueous sulfuric acid and vanadium, they swell, but with different magnitudes. Increased equivalent weight increases the extent of swelling in both non-reinforced and reinforced membranes. As a result, the higher equivalent weight membranes impose extra resistance to vanadium crossover via the increased diffusion path-length, ultimately reducing capacity fade. Comparing the pure cast and GORE-SELECT ${ }^{\circledR}$ membranes, reinforcement decreases the degree of membrane swelling. However, the degree of vanadium crossover mitigation significantly increases as a function of reinforcement, as well. Since the impact of reinforcement on permeability is greater than that of through-plane swelling, reinforced ion-exchange membranes with higher equivalent weight best mitigate vanadium crossover. The results of this study should provide 
deeper insight for ion-exchange membrane developers seeking optimized membrane structures for reduced vanadium ion and water crossover.

Supplementary Materials: The following are available online at http:/ /www.mdpi.com/2077-0375/7/2/29/s1: Figure S1: Calibration spectra for detection of the V(IV) ion via UV-Vis spectroscopy; Figure S2: Area-specific resistance $\left(\Omega \cdot \mathrm{cm}^{2}\right)$; Figure S3: Semi-natural log plot used to determine permeability based on V(IV) ion diffused concentration.

Acknowledgments: Yasser Ashraf Gandomi would like to acknowledge the University of Tennessee for providing a Chancellors Graduate Fellowship. The authors also thank W.L. Gore for providing the ion-exchange membranes and fruitful discussions.

Author Contributions: All authors contributed extensively to this work. Yasser Ashraf Gandomi conceived of and executed the experimental studies. Yasser Ashraf Gandomi and Doug S. Aaron wrote the paper. Matthew M. Mench supervised and guided the project.

Conflicts of Interest: The authors declare no conflict of interest.

\section{Nomenclature}

$V_{v_{-} d} \quad$ Volume of the vanadium-deficient electrolyte $\left(\mathrm{m}^{3}\right)$

$C_{v_{-} d} \quad$ Concentration of $\mathrm{V}(\mathrm{IV})$ ion in vanadium-deficient electrolyte $\left(\mathrm{mol} / \mathrm{m}^{3}\right)$

$C_{v_{-} e} \quad$ Concentration of V(IV) ion in vanadium-enriched electrolyte $\left(\mathrm{mol} / \mathrm{m}^{3}\right)$

$P_{V(I V)}^{m} \quad$ Permeability of V(IV) ion through membrane $m\left(\mathrm{~m}^{2} / \mathrm{s}\right)$

$t_{m} \quad$ Thickness of ion-exchange membrane $(\mathrm{m})$

A Area of the ion-exchange membrane $\left(\mathrm{m}^{2}\right)$

$\Lambda_{V(I V)}^{m} \quad$ Diffusive transport parameter of V(IV) ion through membrane $m(\mathrm{~m} / \mathrm{s})$

\section{References}

1. Weber, A.Z.; Mench, M.M.; Meyers, J.P.; Ross, P.N.; Gostick, J.T.; Liu, Q. Redox flow batteries: A review. J. Appl. Electrochem. 2011, 41, 1137-1164. [CrossRef]

2. Aaron, D.S.; Liu, Q.; Tang, Z.; Grim, G.; Papandrew, A.; Turhan, A.; Zawodzinski, T.A.; Mench, M.M. Dramatic performance gains in vanadium redox flow batteries through modified cell architecture. J. Power Sources 2012, 206, 450-453. [CrossRef]

3. Sum, E.; Skyllas-Kazacos, M. A study of the V(II)/V(III) redox couple for redox flow cell applications. J. Power Sources 1985, 15, 179-190. [CrossRef]

4. Sum, E.; Rychcik, M.; Skyllas-Kazacos, M. Investigation of the $V(V) / V(I V)$ system for use in the positive half-cell of a redox battery. J. Power Sources 1985, 16, 85-95. [CrossRef]

5. Pezeshki, A.M.; Clement, J.T.; Veith, G.M.; Zawodzinski, T.A.; Mench, M.M. High performance electrodes in vanadium redox flow batteries through oxygen-enriched thermal activation. J. Power Sources 2015, 294, 333-338. [CrossRef]

6. Dennison, C.; Agar, E.; Akuzum, B.; Kumbur, E. Enhancing mass transport in redox flow batteries by tailoring flow field and electrode design. J. Electrochem. Soc. 2016, 163, A5163-A5169. [CrossRef]

7. Li, L.; Kim, S.; Wang, W.; Vijayakumar, M.; Nie, Z.; Chen, B.; Zhang, J.; Xia, G.; Hu, J.; Graff, G. A stable vanadium redox-flow battery with high energy density for large-scale energy storage. Adv. Energy Mater. 2011, 1, 394-400. [CrossRef]

8. Leung, P.; Li, X.; de León, C.P.; Berlouis, L.; Low, C.J.; Walsh, F.C. Progress in redox flow batteries, remaining challenges and their applications in energy storage. RSC Adv. 2012, 2, 10125-10156. [CrossRef]

9. Skyllas-Kazacos, M.; Chakrabarti, M.; Hajimolana, S.; Mjalli, F.; Saleem, M. Progress in flow battery research and development. J. Electrochem. Soc. 2011, 158, R55-R79. [CrossRef]

10. Zhou, X.; Zeng, Y.; Zhu, X.; Wei, L.; Zhao, T.S. A high-performance dual-scale porous electrode for vanadium redox flow batteries. J. Power Sources 2016, 325, 329-336. [CrossRef]

11. Derr, I.; Fetyan, A.; Schutjajew, K.; Roth, C. Electrochemical analysis of the performance loss in all vanadium redox flow batteries using different cut-off voltages. Electrochim. Acta 2016, 224, 9-16. [CrossRef]

12. Pezeshki, A.M.; Sacci, R.L.; Veith, G.M.; Zawodzinski, T.A.; Mench, M.M. The cell-in-series method: A technique for accelerated electrode degradation in redox flow batteries. J. Electrochem. Soc. 2016, 163, A5202-A5210. [CrossRef] 
13. Knehr, K.; Agar, E.; Dennison, C.; Kalidindi, A.; Kumbur, E. A transient vanadium flow battery model incorporating vanadium crossover and water transport through the membrane. J. Electrochem. Soc. 2012, 159, A1446-A1459. [CrossRef]

14. Tang, A.; Bao, J.; Skyllas-Kazacos, M. Dynamic modelling of the effects of ion diffusion and side reactions on the capacity loss for vanadium redox flow battery. J. Power Sources 2011, 196, 10737-10747. [CrossRef]

15. Ashraf Gandomi, Y.; Aaron, D.S.; Mench, M.M. Coupled membrane transport parameters for ionic species in all-vanadium redox flow batteries. Electrochim. Acta 2016, 218, 174-190. [CrossRef]

16. Wiedemann, E.; Heintz, A.; Lichtenthaler, R. Transport properties of vanadium ions in cation exchange membranes: Determination of diffusion coefficients using a dialysis cell. J. Membr. Sci. 1998, 141, 215-221. [CrossRef]

17. Sun, C.; Chen, J.; Zhang, H.; Han, X.; Luo, Q. Investigations on transfer of water and vanadium ions across nafion membrane in an operating vanadium redox flow battery. J. Power Sources 2010, 195, 890-897. [CrossRef]

18. Xi, J.; Wu, Z.; Qiu, X.; Chen, L. Nafion $/ \mathrm{SiO}_{2}$ hybrid membrane for vanadium redox flow battery. J. Power Sources 2007, 166, 531-536. [CrossRef]

19. Xie, W.; Darling, R.M.; Perry, M.L. Processing and pretreatment effects on vanadium transport in nafion membranes. J. Electrochem. Soc. 2016, 163, A5084-A5089. [CrossRef]

20. Yang, X.-G.; Ye, Q.; Cheng, P.; Zhao, T.S. Effects of the electric field on ion crossover in vanadium redox flow batteries. Appl. Energy 2015, 145, 306-319. [CrossRef]

21. Darling, R.M.; Weber, A.Z.; Tucker, M.C.; Perry, M.L. The influence of electric field on crossover in redox-flow batteries. J. Electrochem. Soc. 2016, 163, A5014-A5022. [CrossRef]

22. Lawton, J.S.; Jones, A.; Zawodzinski, T. Concentration dependence of $\mathrm{VO}^{2+}$ crossover of nafion for vanadium redox flow batteries. J. Electrochem. Soc. 2013, 160, A697-A702. [CrossRef]

23. Elgammal, R.A.; Tang, Z.; Sun, C.-N.; Lawton, J.; Zawodzinski, T.A. Species uptake and mass transport in membranes for vanadium redox flow batteries. Electrochim. Acta 2017, 237, 1-11. [CrossRef]

24. Ashraf Gandomi, Y.; Zawodzinski, T.A.; Mench, M.M. Concentrated solution model of transport in all vanadium redox flow battery membrane separator. ECS Trans. 2014, 61, 23-32. [CrossRef]

25. Ashraf Gandomi, Y.; Edmundson, M.D.; Busby, F.C.; Mench, M.M. Water management in polymer electrolyte fuel cells through asymmetric thermal and mass transport engineering of the micro-porous layers. J. Electrochem. Soc. 2016, 163, F933-F944. [CrossRef]

26. Ashraf Gandomi, Y.; Mench, M.M. Assessing the limits of water management using asymmetric micro-porous layer configurations. ECS Trans. 2013, 58, 1375-1382. [CrossRef]

27. Ashraf Gandomi, Y.; Aaron, D.S.; Zawodzinski, T.A.; Mench, M.M. In situ potential distribution measurement and validated model for all-vanadium redox flow battery. J. Electrochem. Soc. 2016, 163, A5188-A5201. [CrossRef]

28. Won, S.; Oh, K.; Ju, H. Numerical analysis of vanadium crossover effects in all-vanadium redox flow batteries. Electrochim. Acta 2015, 177, 310-320. [CrossRef]

29. Weber, A.Z.; Borup, R.L.; Darling, R.M.; Das, P.K.; Dursch, T.J.; Gu, W.; Harvey, D.; Kusoglu, A.; Litster, S.; Mench, M.M.; et al. A critical review of modeling transport phenomena in polymer-electrolyte fuel cells. J. Electrochem. Soc. 2014, 161, F1254-F1299. [CrossRef]

30. Darling, R.; Gallagher, K.; Xie, W.; Su, L.; Brushett, F. Transport property requirements for flow battery separators. J. Electrochem. Soc. 2016, 163, A5029-A5040. [CrossRef]

31. Luo, J.; Conrad, O.; Vankelecom, I.F.J. Imidazolium methanesulfonate as a high temperature proton conductor. J. Mater. Chem. A 2013, 1, 2238-2247. [CrossRef]

32. Luo, J.; Conrad, O.; Vankelecom, I.F.J. Physicochemical properties of phosphonium-based and ammonium-based protic ionic liquids. J. Mater. Chem. 2012, 22, 20574-20579. [CrossRef]

33. Viswanathan, V.; Crawford, A.; Stephenson, D.; Kim, S.; Wang, W.; Li, B.; Coffey, G.; Thomsen, E.; Graff, G.; Balducci, P.; et al. Cost and performance model for redox flow batteries. J. Power Sources 2014, 247, 1040-1051. [CrossRef]

34. Darling, R.M.; Gallagher, K.G.; Kowalski, J.A.; Ha, S.; Brushett, F.R. Pathways to low-cost electrochemical energy storage: A comparison of aqueous and nonaqueous flow batteries. Energy Environ. Sci. 2014, 7, 3459-3477. [CrossRef] 
35. Luo, Q.; Li, L.; Nie, Z.; Wang, W.; Wei, X.; Li, B.; Chen, B.; Yang, Z. In-situ investigation of vanadium ion transport in redox flow battery. J. Power Sources 2012, 218, 15-20. [CrossRef]

36. De Leon, C.P.; Frías-Ferrer, A.; González-García, J.; Szánto, D.; Walsh, F.C. Redox flow cells for energy conversion. J. Power Sources 2006, 160, 716-732. [CrossRef]

37. Sepehr, F. Multiscale modeling of electrolytes for energy storage and conversion. Univ. Tenn. $2016,92$. Available online: http:/ / trace.tennessee.edu/utk_graddiss/4165 (accessed on 11 February 2017).

38. Humplik, T.; Lee, J.; O’hern, S.; Fellman, B.; Baig, M.; Hassan, S.; Atieh, M.; Rahman, F.; Laoui, T.; Karnik, R. Nanostructured materials for water desalination. Nanotechnology 2011, 22, 292001. [CrossRef] [PubMed]

39. Humplik, T.; Raj, R.; Maroo, S.C.; Laoui, T.; Wang, E.N. Effect of hydrophilic defects on water transport in MFI zeolites. Langmuir 2014, 30, 6446-6453. [CrossRef] [PubMed]

40. Fasano, M.; Humplik, T.; Bevilacqua, A.; Tsapatsis, M.; Chiavazzo, E.; Wang, E.N.; Asinari, P. Interplay between hydrophilicity and surface barriers on water transport in zeolite membranes. Nat. Commun. 2016, 7, 12762. [CrossRef] [PubMed]

41. Yousefzadi Nobakht, A.; Shin, S. Anisotropic control of thermal transport in graphene/Si heterostructures. J. Appl. Phys. 2016, 120. [CrossRef]

(C) 2017 by the authors. Licensee MDPI, Basel, Switzerland. This article is an open access article distributed under the terms and conditions of the Creative Commons Attribution (CC BY) license (http:/ / creativecommons.org/licenses/by/4.0/). 